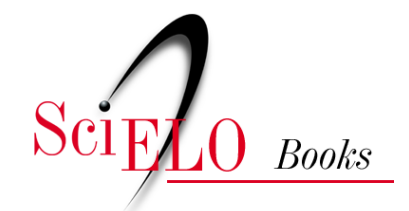

uer

\title{
Capítulo 4 \\ Cotidiano, cultura, alteridade e a criação permanente de diferença
}

\author{
Carlos Eduardo Ferraço \\ Maria da Conceição Silva Soares \\ Nilda Alves
}

\section{SciELO Books / SciELO Livros / SciELO Libros}

FERRAÇO, C.E., SOARES, M.C.S., AND ALVES, N. Cotidiano, cultura, alteridade e a criação permanente de diferença. In: Michel de Certeau e as pesquisas nos/dos/com os cotidianos em educação [online]. Rio de Janeiro: EdUERJ, 2018, pp. 71-88. ISBN 978-85-7511-517-6.

https://doi.org/10.7476/9788575115176.0005.

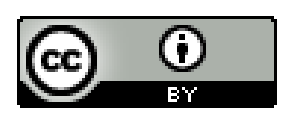

All the contents of this work, except where otherwise noted, is licensed under a Creative Commons Attribution 4.0 $\underline{\text { International license. }}$

Todo o conteúdo deste trabalho, exceto quando houver ressalva, é publicado sob a licença Creative Commons Atribição $\underline{4.0}$.

Todo el contenido de esta obra, excepto donde se indique lo contrario, está bajo licencia de la licencia $\underline{\text { Creative Commons }}$ Reconocimento 4.0. 


\section{CAPÍTULO 4}

\section{Cotidiano, cultura, alteridade e a criação permanente de diferença}

No ocidente, o grupo (ou indivíduo) se robustece com aquilo que exclui (é a criação de um lugar próprio) e encontra sua segurança na confissão que extrai de um dominado (assim se constitui o saber de/sobre o outro, ou ciência humana) (Certeau, 2006, p. 17).

Toda ciência humana deve introduzir a suspeita em seu próprio desenvolvimento para interrogar sobre sua relação histórica com um tipo social. Ela está vinculada a uma forma de cultura. Para se definir novamente, deve fazer uma análise contestadora da civilização que ela postula (Certeau, 1995, p. 173).

Michel de Certeau foi um homem antenado com os movimentos sociais, políticos, artísticos e intelectuais do seu tempo, mais precisamente com aqueles que se engendraram entre os anos 1960 e 1990, e agitaram tanto Paris quanto a Califórnia, além do Rio de Janeiro, de Salvador e de tantos outros lugares nos quais viveu e/ou visitou, e onde experimentou e destacou singularidades, mestiçagens, engenhosidades, inventividades, conveniências e pequenas liberdades forjadas com as práticas cotidianas na contingência das chamadas "cultura de massa" e/ou "sociedade de consumo", as quais se tornaram os principais objetos elaborados por inúmeros estudos, apocalípticos ou integrados, das ciências sociais e humanas à época.

Em meio a esses movimentos, em que modelos explicativos como o marxismo, o estruturalismo e o funcionalismo co- 
meçaram a serem postos em xeque, Certeau, de alguma forma, foi afetado pela "virada culturalista", pela "virada linguística", pela psicanálise, por alguns pressupostos do pós-estruturalismo, pela Escola dos Annales, assim como por outras críticas a esses modelos teleológicos e comprometidos com o Iluminismo.

Da mesma forma, deixou-se atravessar pelos movimentos das ruas, como o Maio de 1968 na França, as guerrilhas na América do Sul, África e Ásia, as guerras pela independência nas ex-colônias, as migrações pós-coloniais, as reivindicações de minorias raciais, étnicas, de gênero, de geração, de região geopolítica, entre outras, bem como pelo desenvolvimento da "indústria cultural" e das mídias, em especial, pela televisão. Todas essas afetações não o levaram a filiar-se a nenhuma tendência ou escola de pensamento, mas ajudaram-no a criar uma "ciência prática do singular".

Sensível a esses movimentos, o intelectual conhecido por estudar a mística religiosa na Idade Média, dedicou-se também à investigação das transformações culturais que vinham ocorrendo em vários pontos do planeta na segunda metade do século XX, deslocando para a investigação do presente algumas noções que lhe eram úteis em seus trabalhos no campo da teologia, tais como a ideia de métis, a inteligência prática e astuciosa dos heróis e deuses analisada por Detienne e Vernant (2008) a partir de um estudo da mitologia, e a importância dos gestos, mais precisamente da moral dos gestos, a partir da relevância destes nos rituais religiosos, cuja reflexão a respeito teria sido realizada, de acordo com Schmitt (2005), em grande parte, por pensadores cristãos. Essas noções foram apropriadas em suas análises da cultura como criação anônima que se forja por palavras e gestos que se coengendram com as práticas cotidianas 
(verbais e não verbais) dos homens e mulheres ordinários, produzindo sempre diferença, heterogênese, multiplicidades.

Certeau, portanto, não se deteve, demorada e diretamente, sobre a questão da identidade e da diferença cultural (ambas, o modelo e seu negativo, entendidas como formas originárias, fixas, puras, opostas e excludentes), tal qual ela seria, algumas vezes, exposta por outras abordagens dentro dos Estudos Culturais, inclusive nas pesquisas em educação. Embora tenha legitimado e defendido a mobilização e a organização das minorias em torno de reivindicações para que as políticas públicas lhes garantissem seus direitos, ele preocupou-se, principalmente, com a produção de "lugares próprios" no contexto das relações de forças, do exercício do poder.

Tratava-se de desnaturalizar as operações que levam os discursos produzidos em tais lugares a falarem em nome do real e da verdade sobre o Outro, silenciando-o e fabricando os modos como ele deve ser percebido, subjetivado, objetivado, assistido, dominado, controlado e governado. Certeau (1995, p. 232) se debruçou, por exemplo, sobre o lugar próprio instituído pela ciência de uma forma geral e pela história em particular para desocultar os modos pelos quais procedimentos hegemônicos nessas instituições constituíram/constituem "todo o seu resto", ou seja, a "cultura" e "os outros", propondo outra atitude epistemológica: a relação, a confrontação, a legitimação e a comparação com as alteridades, as quais constituem o modo como "o futuro entra no presente".

Ao mesmo tempo em que se dedicava ao estudo das operações que constituem os "lugares próprios", Michel de Certeau voltava-se para a astúcia desses "Outros" do saber/poder ao produzirem com seus modos de fazersaber, informados por seus 
desejos, interesses e referências, desordens e deslocamentos em tais lugares, instituindo, permanentemente, diferença.

A identidade, nessa perspectiva, é pretensão, modelo vazio. A ordem e as normas impostas pelos saberesfazeres criados nesses "lugares próprios", como, por exemplo, a autoridade cultural, são, todo tempo, subvertidas pelos desvios produzidos com as práticas: "a força anônima de uma dor, de uma cólera ou de uma gargalhada da multidão acaba por cativar, inquietar, às vezes invadir e destruir o edifício do saber” (Certeau, 2011, p. 127). Essa lógica operatória, como a métis, "não se manifesta abertamente pelo que ela é", não se mostra ao pensamento com clareza, "ela aparece sempre mais ou menos 'nos vãos', imersa numa prática que não se preocupa [...] em explicar sua natureza, nem em justificar seu procedimento" (Detienne e Vernant, 2008, p. 11).

Essa modalidade de ação, que "exerce-se sobre um terreno móvel, em uma situação incerta e ambígua" (Detienne e Vernant, 2008, p. 21), na qual duas forças antagônicas se enfrentam, remonta, segundo Certeau, a experiências milenares e pode instituir espaços de liberdade e diferença mesmo onde se supõe apenas o domínio e a assimilação, como no seio da colonização. Para o autor (1994, pp. 39-40),

Há bastante tempo que se tem estudado que equívoco rachava, por dentro, o 'sucesso' dos colonizadores espanhóis entre as etnias indígenas: submetidos e mesmo consentindo na dominação, muitas vezes esses indígenas faziam das ações rituais, representações ou leis que lhes eram impostas outra coisa que não era o que o conquistador julgava obter por elas. Os indígenas as subvertiam, não rejeitando-as diretamente ou modificando-as, mas pela sua maneira de usá-las para fins e em função de referências estranhas ao sistema do qual não podiam fugir. Eles eram outros, mesmo no seio da colonização 
que os 'assimilava' exteriormente; seu modo de usar a ordem dominante exercia o seu poder, que não tinham meios para recusar; a esse poder escapavam sem deixá-lo. A força de sua diferença se mantinha nos procedimentos de 'consumo'. Em grau menor, um equívoco semelhante se insinua em nossas sociedades com o uso que os meios 'populares' fazem das culturas difundidas e impostas pelas 'elites' produtoras de linguagem.

Para Michel de Certeau (1194, p. 40), a presença ou a circulação de uma representação ensinada por "pregadores, educadores ou por vulgarizadores", não garante o que ela é para seus usuários. Somente ao analisarmos os usos que são feitos dessa representação é que podemos apreciar a diferença entre a produção da imagem e a produção secundária que se realiza nos processos de sua utilização. A ênfase dada pelo autor está, portanto, preferencialmente na performatividade das práticas e na diferença que elas criam em relação aos sistemas de referência que lhe são estranhos, e não, exclusivamente, na performatividade do discurso, da imagem, da lei, do endereçamento, da representação e na repetição que tais normativas sugerem.

O próprio trabalho de Certeau situou-se nessa diferença e operou uma inversão de perspectiva na abordagem da cultura, circunscrevendo um domínio de investigação no qual as pesquisas nos/com os cotidianos em educação se inscrevem e o qual buscam desenvolver para dar visibilidade e inteligibilidade às operações de praticantes e ao que com elas se cria. Nessa perspectiva, para nós, assim como para Certeau:

O que importa já não é, nem pode ser mais a 'cultura erudita', tesouro abandonado à vaidade dos seus proprietários. Nem tampouco a chamada 'cultura popular', 
nome outorgado de fora por funcionários que inventariam e embalsamam aquilo que um poder já eliminou, pois para eles e para o poder 'a beleza do morto' é tanto mais emocionante e celebrada quanto melhor encerrada no túmulo. Sendo, é necessário voltar-se para a 'proliferação disseminada' de criações anônimas e 'perceptíveis' que irrompem com vivacidade e não se capitalizam (Giard, 1994, p. 13).

A concepção de cultura como redes de criações anônimas e práticas significantes foram emergindo na obra de Certeau em um pensamento que se forjava em meio a mudanças sociais, políticas e intelectuais e que buscava dar conta de um presente em construção. Na obra também manifestou-se a noção de poder como relação que se exerce em toda parte e como algo que ninguém possui, mas que está sempre sendo disputado, embora implique autoridade e força.

Ainda que tenhamos poucos registros a respeito de possíveis debates acadêmicos travados em presença com outros pensadores a ele contemporâneos, encontramos na obra de Certeau vestígios de encontros, diálogos e atravessamentos com outros intelectuais de seu tempo conhecidos em nosso campo da educação, tais como Edgar Morin, Gilles Deleuze, Marc Augé, Bruno Latour, Pierre Bourdieu, Jacques Derrida e Michel Foucault. Algumas problemáticas comuns e noções compartilhadas nos apontam para frequentações e solidariedades intelectuais entre eles, para além das questões manifestas nas conversas explicitadas que Certeau estabeleceu com alguns desses e com outros pensadores em seus livros, quase sempre para desenvolver pensamentos análogos e ao mesmo tempo contrários aos de seus intercessores. 
Entre esses pensadores, por conta do tema abordado nesse capítulo, buscamos uma aproximação com Michel Foucault, por quem, segundo Giard (2011), Certeau tinha não só amizade como também admiração. Com Foucault, Certeau partilhava a necessidade de criar modos pelos quais fosse possível "pensar diferentemente", e destacava, no amigo, a atitude de estranhamento e atenção vigilante para as "citações do impensado". E, ao falar da empreitada teórica de Foucault, Certeau nos dá pistas sobre o que, em comum, entendiam por maneiras de praticar o poder, entre as quais se situam as atividades intelectuais. Como analisa Certeau (2011, pp. 125-6),

Na perspectiva delineada por Michel Foucault, entendo por práticas de poder 'um modo de ação que não age, direta e imediatamente, sobre os outros, mas sobre a ação própria deles'; tais práticas compõem 'um conjunto de ações sobre ações possíveis' (Foucault, 1984). Trata-se, portanto de operações (procedimentos) e não de concepções (ideias), embora elas possam situar-se nos dois registros que, em proporções, variáveis, qualquer poder implica: por um lado, uma autoridade (relativa ao crer/fazer crer); e por outro uma força (relativa a uma pressão ou repressão física).

Para empreendermos a inversão na perspectiva de abordagem da diferença nos diversos contextos culturais cotidianos compreendendo-a como afirmativa e criadora de outras possibilidades para a existência e para o conhecimento, precisamos pensar o poder como um exercício, uma relação de forças, uma luta travada todo dia por indivíduos e grupos sociais, em todos os espaçostempos em que os seres humanos se encontram e se relacionam. Em meio a esse exercício, para manter ou conquistar 
reconhecimento e os benefícios que dele advêm, os praticantes inventam-se a si mesmo e criam cultura.

\section{As Culturas e suas redes de operações}

A cultura oscila mais essencialmente entre duas formas, das quais uma sempre faz com que se esqueça da outra. De um lado ela é aquilo que 'permanece'; do outro aquilo que se inventa. Há, por um lado, as lentidões, as latências, os atrasos que se acumulam na espessura das mentalidades, certezas e ritualizações sociais, via opaca, inflexível, dissimulada nos gestos cotidianos, ao mesmo tempo os mais atuais e milenares. Por outro lado, as irrupções, os desvios, todas essas margens de uma inventividade de onde as gerações futuras extrairão sucessivamente sua 'cultura erudita'. A cultura é uma noite escura em que dormem as revoluções de há pouco, invisíveis, encerradas nas práticas -, mas pirilampos, e por vezes grandes pássaros noturnos, atravessam-na; aparecimentos e criações que delineiam a chance de um outro dia (Certeau, 1995, p. 239).

Certeau foi impelido a mergulhar nessa "noite oceânica", que o instigava e inquietava, como ele mesmo afirmou, em meio ao calor das manifestações de maio de 1968, quando escreveu artigos sobre os "acontecimentos" para a revista Études (periódico sobre cultura publicado pela Companhia de Jesus) e quando colaborou com diversos pareceres, pesquisas e reflexões acadêmicas sobre esse tema, bem como com estruturas de governo na França voltadas para a criação de políticas sociais e culturais nas contingências das mudanças em andamento (Giard, 1995). Recusando-se a uma concepção de cultura no singular, isto é, da cultura da elite tomada como "a cultura", e convencido de que a 
invenção e a criatividade não são apanágio dos profissionais do assunto, ele formula uma série de artigos destacando as redes informais que produzem e fazem circular cultura. Esses artigos serão posteriormente reunidos no livro A cultura no plural, cuja primeira versão foi publicada em 1974, em Paris.

Seis anos depois, no prefácio da edição de 1980, toma esse livro como esboço de travessias que produziram outras pesquisas ( $A$ invenção do cotidiano) e indica que tais travessias requerem uma passagem do "plural" ao múltiplo. Essas reflexões posteriores nos ajudam a nos apropriarmos de várias formulações criadas naquela ocasião, deslocando-as e as ressignificando no espaçotempo para pensarmos problemáticas postas pela questão da cultura, da diferença e da alteridade na contemporaneidade. Trata-se de pensar a ação cultural no contexto dos combates cotidianos, onde se engendra uma arte social de jogar com as instituições e hierarquias: "a cultura pode ser comparada com essa arte, condicionada pelos lugares, regras e dados; ela é uma proliferação de invenções em espaços circunscritos" (Certeau, 1995, p. 19).

Ao pensar a cultura como uma rede de operações produtoras de saberesfazeres, poderes e sentidos, Certeau desloca a compreensão de ação cultural ou política como algo realizado de forma centralizada e de cima para baixo, ou seja, pelas estruturas que buscam o governo dos outros, para as redes de práticas sociais cotidianas que produzem sentidos para aqueles que as realizam. Cultura é uma prática significativa. "Ela consiste não em receber, mas em exercer a ação pela qual cada um marca aquilo que outros lhe dão para viver e pensar" (Certeau, 1995, p. 143). Assim, para o autor (p. 142), não há na socieda- 
de setor particular (religião, ideologia, ciência, mercado, mídia etc.) capaz de "fornecer a todos os outros aquilo que os proverá de significação".

Nessa perspectiva, como assinalou Giard (1995, p. 10), as culturas não constituem um conjunto de valores a serem preservados e defendidos, ao contrário, constituem-se como um trabalho a ser realizado em toda extensão da vida social, o qual "requer uma atividade, um modo de apropriação, uma adoção e uma transformação pessoais, um intercâmbio instaurado em um grupo social”. A inversão na abordagem em relação a outras práticasteorias difundidas à época consiste na desapropriação da cultura no singular (apagamento da propriedade e do nome próprio) e, simultaneamente, em uma passagem a práticas de significação, isto é, a operações produtoras.

\section{Violências, minorias e revoluçōes do crível}

Os atos de violência são justamente designados como 'manifestações'. Eles pretendem quebrar e desmascarar a economia alienante do meio e o totalitarismo da identidade. Sob esse ponto de vista, o ultraje torna-se 'paixão moral'. Ele se faz gesto, porque as palavras foram confiscadas. O desordeiro que quebra o visor da calculadora IBM ou a porta do automóvel procede - mas exteriormente ao texto - como o escritor que trabalha na desconstrução da linguagem. A fenda que ele assinala na rede objetiva dos significados é o correspondente de um lapso de linguagem. Esse ato intercepta com um protesto um universo saturado. A repetição do anônimo cria o análogo de um 'ruído' em que a palavra tem inicialmente a forma de uma fratura, de um buraco, de uma blasfêmia (Certeau, 1995, p. 94). 
Ao trazer para a análise o caso extremo do ato violento nas manifestações, o qual ele denomina como práticas do blasfemo, Certeau (1995, p. 95) busca, no contexto do estudo sobre os acontecimentos de Maio de 1968, assinalar a irrupção de um grupo em uma sociedade que tolera cada vez menos os nascimentos: "ele autentica o querer-existir de uma minoria que procura se constituir em um universo onde ela é excedente porque ainda não se impôs”. Tal nascimento é, para ele, indissociável de uma violência, que, no entanto, reside em um discurso de protesto. Ela opera como um sinal, indica a necessidade de mudanças, abre possibilidades. Contudo, tal atitude não cria; desfaz, mas não instaura. Cabe, então, a tarefa infindável de construir sociedades sobre razões para viver próprias a todos e cada um.

O nascimento das minorias, conforme o entendimento do autor, é forjado por, ao mesmo tempo em que forja, revoluções no crível, as quais levam ao descrédito das autoridades vivenciado por todos.

Os dogmas, os saberes, os programas e as filosofias perdem sua credibilidade, sombras sem corpos que nem a mão, nem o espírito podem capturar e cuja evanescência irrita ou engana o gesto que ainda os procura; eles nos deixam, muitas vezes persistentemente, apenas a ilusão ou a vontade de 'sustentá-los' (Certeau, 1995, p. 27).

Nessas contingências, as autoridades socioculturais tornam-se absurdas por não corresponderem mais à geografia do sentido e os grupos sociais marginalizados, excluídos e/ou inaugurais recusam a não significação e buscam razões comuns para viver. Trata-se do direito de um grupo social formular seus quadros de referência e seus modelos de comportamento. Surgem, 
então, credibilidades nascentes que informam o que há de móvel e de inventivo na vida social. Emergem sinais, crenças e acordos tácitos que tornam possível a elaboração de um comum.

Tais credibilidades nascentes, contudo, não se dizem diretamente e expressam-se por meio do que negam e do que aceitam, do que se apropriam e do que consideram essencial para viver. As revoluções do crível não são, segundo Certeau, reivindicadoras. São discretas e mais terríveis, pois produzem descolamentos na adesão, reorganizando as autoridades aceitas, privilegiando algumas referências e eliminando outras.

\section{Cotidiano, comportamento e reconhecimento}

A noção de conveniência foi desenvolvida no livro $A$ invenção do cotidiano (v. 2), por Pierre Mayol, um dos pesquisadores do grupo dirigido por Michel de Certeau, com base em premissas por ele sugeridas. Trouxemos essa discussão para este capítulo porque entendemos que ela indica um modo de pensar a organização da vida cotidiana através da articulação entre dois registros: os comportamentos e os benefícios simbólicos que se espera adquirir ou conservar, o que pode nos ajudar a pensar a performatividade das práticas na questão dos processos identitários e de diferenciação. Segundo esse pesquisador, a conveniência:

representa, no nível dos comportamentos, um compromisso pelo qual cada pessoa, renunciando à anarquia das pulsões individuais, contribui com sua cota para a vida coletiva, com o fito de daí retirar benefícios simbólicos necessariamente protelados. Por esse 'preço a pagar' (saber 'comportar-se', ser 'conveniente'), o usuário se torna parceiro de um contrato social que ele se obriga a respeitar para que seja possível a vida cotidiana. [...] A contrapartida desse tipo de imposição é para o usuá- 
rio a certeza de ser reconhecido, 'considerado' por seus pares, e fundar assim em benefício próprio uma relação de forças nas diversas trajetórias que percorre (Mayol, 1996, p. 39).

Pensando por esse prisma, ao invés de passivo e manipulado pelas autoridades culturais, o praticante da cultura age, joga o jogo da conveniência em benefício próprio, conserva-se atrás de uma máscara para sair-se bem em seu papel social e altera com seus movimentos as regras do jogo. Para Mayol (1996, p. 40), a prática cultural implica uma combinação, mais ou menos fluida, mais ou menos coerente, de elementos cotidianos (concretos, ideológicos, simbólicos, tradicionais, institucionais) realizada dia a dia através de comportamentos que "traduzem em visibilidade fragmentos desse dispositivo cultural". Essa operação possibilita ao usuário criar e assumir uma identidade na rede das relações sociais inscritas em um ambiente, mantendo-se "na defesa" no interior de códigos sociais em situações de coexistência indecidível e inevitável, em que "sair à rua significa o risco de ser reconhecido, e portanto apontado com o dedo" (Mayol, 1996, p. 47). A ênfase na palavra comportamento, segundo o autor (p.48), indica que o corpo é suporte primeiro da mensagem social proferida:

O corpo é o suporte de todas as mensagens gestuais que articulam essa conformidade: é um quadro-negro onde se escrevem - e portanto se fazem legíveis - o respeito aos códigos ou ao contrário o desvio com relação ao sistema de comportamentos. 
O corpo e seus acessórios, palavras e gestos, têm uma função fundamental no processo de funcionamento da conveniência, cujo estilo de ação - manter-se atrás da máscara favorece uma inserção indefinida, baseada no consentimento e não na coação, no tecido coletivo.

A noção de conveniência possibilitou a Mayol, por exemplo, pensar práticas do espaço público levando em conta a suposta diferença entre os sexos, e permitindo a ele constatar que a ambígua organização sexuada do espaço é constantemente subvertida pelos passos dos usuários, pelos itinerários que criam e pelas práticas de significação que engendram, criando sentidos imprevistos no texto da conveniência.

Certeau e Giard (1996) ao discorrerem sobre a mítica da cidade, destacam que na perspectiva de uma nova estética urbana duas redes retêm particular atenção: os gestos e os relatos. Segundo eles, as duas cadeias de operações, uma tática e outra linguística, deslocam objetos, normas e regras modificando-lhes o emprego e reorganizando os espaços.

O dispositivo da conveniência pode nos ser útil para pensar a questão da identidade não necessariamente como um modelo imposto de cima pra baixo, mas como o resultado da uma adesão a um acordo, uma máscara que possibilita reconhecimento, um saber jogar o perde-ganha que implica renúncia e conquista dos benefícios almejados.

\section{Pesquisar a diferença nos cotidianos das escolas}

O que Certeau nos propõe é pensar "outramente" a diferença nos diversos contextos cotidianos, entre eles as escolas e as redes educativas que as atravessam. Para isso, precisamos, em nossas pesquisas nos/dos/com os cotidianos, de posturas epistemoló- 
gicas, teóricas e metodológicas que nos possibilitem, além de indicar os mecanismos de homogeneização e as dinâmicas de exclusão, repressão e controle exercidos supostamente apenas por um poder centralizador e determinista (articulado em diversos contextos, como o político, o econômico, o cultural, o científico, o religioso etc.), enxergar os usos que os praticantes dos cotidianos escolares fazem deles e os desvios que esses usos produzem, instituindo, permanentemente, diferença. Nessa perspectiva, torna-se relevante compreender os cotidianos como campos de luta, nos quais o poder, como relação de forças, está sempre sendo contestado e disputado. Precisamos, ainda, indicar a multiplicidade de modos de existência e de conhecimentos que, com essas operações de usuários, se engendram e singularizam criando cultura e produzindo sentidos.

Partindo da noção de complexidade como uma das características das redes de operatórias produtoras do sociocultural e na necessidade de pensar paradoxalmente que essa compreensão exige, a dicotomia identidade/diferença (como negativo da primeira) não nos serve mais para pensar a diferença afirmativa e a multiplicidade que se produzem, constantemente, nos/com os cotidianos escolares, ainda que esse modo de pensar tenha possibilitado uma posição de partida importante. Conforme Certeau (1995, p. 145):

Um certo número de movimentos minoritários enfrenta a dificuldade de ter, em um primeiro momento, que se situar negativamente. Uma autonomia cultural, social ou étnica sempre se manifesta dizendo não: Não diz o negro, não sou um americano. Não diz o indiano, não sou um chileno ou um argentino. Não diz o bretão, não sou um francês. Essa é uma posição de partida absolutamente fundamental, mas rapidamente se torna 
enganosa quando se permanece nela: corre-se o risco de se agarrar quer a uma ideologia política, quer a uma formulação exclusivamente cultural.

Entretanto, para Certeau (1995), permanecer nessa posição é entrar no jogo que construiu o cultural como espetáculo e que instaura os elementos culturais como objetos de uma comercialização. Ademais, nessa dicotomia, a referência é sempre o que é hegemônico em determinado espaçotempo, produzindo no outro um sentimento de ser "diferente" ligado à designação dessa diferença pelo grupo dominante nessa circunstância, o que diminui a sua autonomia. $\mathrm{O}$ autor destaca ainda que os movimentos das minorias levantam uma questão geral relativa a toda a sociedade e indica que não há autonomia sem luta.

Assim compreendendo, defendemos que é possível examinar as práticas, entre elas, as acadêmicas e educativas, as que os produzem como tal. Mais do que dar visibilidade ao "diferente", como objeto do conhecimento, essência, categoria fixa ou fixada, resultado do grupamento de pessoas a partir de apenas um dos vários aspectos que as constituem, e que é ao mesmo tempo o negativo da identidade.

Da mesma maneira, a irredutibilidade de cada pessoa a um único aspecto de sua subjetividade, ao mesmo tempo única-múltipla, seja aquele informado pela significação atribuída à cor da pele, à genitália, à orientação sexual, à região geopolítica em que habita, à religião, à condição socioeconômica etc., nos leva a considerar que qualquer classificação é uma arbitrariedade, resultado de uma operação de significação metonímica (o todo por uma parte, física ou comportamental), e, assim, uma tentativa de reduzir a complexidade que constitui cada pessoa. Ao invés de potencializar essa operação, seria melhor, portanto, problematizá-la. Um caminho para essa problematização foi apontado pelo próprio Certeau (1994), quando propôs que con- 
siderássemos os sujeitos da vida cotidiana como praticantes, $\mathrm{o}$ que implica capturá-los não em essência (o que são, que cremos que são ou queremos que sejam), mas em atos.

A ideia de multiplicidade, como característica inerente ao cotidiano, nos leva a pensar que o que se produz com as práticas são diferenças, sendo as identidades, nessa perspectiva, dissimulações em relação a modelos vazios. A diferenciação, como processo, é o que caracteriza não só o movimento browniano da criação cultural, mas também própria vida. A diferença processual em relação não apenas aos outros, como a si mesmo, é, portanto, o que deve nos interessar. A afirmação da diferença, como processo vital e expansivo, desvinculada da identidade, da formatização da vida, das moldagens e das modulações é o que nos importa valorizar. Mas como afirmar que só existe diferença sem cair na indiferença em relação a todos aqueles marginalizados, subalternizados e/ou excluídos politicamente, socialmente e culturalmente em nossas sociedades?

Talvez, problematizando as operações que os produziram como "diferentes", como anormais, como minorias, para assim justificar a desigualdade produzida por essas e também por outras práticas (científicas, econômicas, bélicas, midiáticas, pedagógicas etc.). Talvez ainda, fazendo aparecer a complexidade e a multiplicidade que existe nos cotidianos, as negociações, as máscaras, os usos e as astúcias que produzem mestiçagens e põem em xeque, todo o tempo, as classificações.

Além, disso, uma tarefa nos foi proposta por Certeau (1995): a criação de razões para viver que sejam potentes para todos e para cada um. No que diz respeito a nós, educadores e pesquisadores, essa tarefa impõe, como questão de fundo, colocar em "debate o lugar do intelectual na sociedade e a experiência ou a concepção de cultura que resulta disso" (1995, p. 227). 
Trata-se ainda de assinalar a particularidade do nosso lugar e as dependências que ele implica.

Certeau, ao analisar os acontecimentos de seu tempo, nos advertiu para a necessidade de estar atentos às heteronomias, aos outros que estão em nós e que nos constituem. "O futuro nos chega às vezes, à nossa revelia, com as formações talvez “anárquicas e confusas", de mundos novos e diferentes" (1995, p. 231). Assim, essa outra sociedade no seio da que vivemos abre no presente possibilidades vindouras. Em resumo, como já havíamos destacado, o "futuro entra no presente sob a forma de alteridades” (p. 232), fazendo com que a vida se produza, sempre, na relação com os Outros. 